\title{
Sociale reorganisatie en bedrijfsresultaat
}

\section{Hendrik Leendert Aalbers en Wilfred Dolfsma}

\section{SAMENVATTING Reorganiseren wordt steeds gebruikelijker en vindt niet alleen} plaats om direct kosten te kunnen besparen. Er is veel bekend over de effecten van reorganiseren voor medewerkers, maar weinig over de vraag naar het effect op het bedrijfsresultaat nadien en naar de wijze waarop gereorganiseerd wordt. Moeten bedrijven zich de stress en onzekerheid bij medewerkers aantrekken en daarom op sociale wijze reorganiseren, of vooral snel kosten reduceren? In het artikel wordt onderzocht in hoeverre het sociale karakter van een reorganisatie het bedrijfsresultaat na de reorganisatie beïnvloedt. De auteurs claimen dat langer de tijd nemen voor reorganisaties gunstig is, dat met reorganiseren niet te lang gewacht moet worden, en dat socialer reorganiseren het bedrijfsresultaat op de korte termijn niet negatief beinvloedt. Hiermee is het artikel een eerste wetenschappelijke bijdrage over de vraag hoe bedrijven het best kunnen reorganiseren in tijden van economische crisis.

\section{RELEVANTIE VOOR DE PRAKTIJK Een reorganisatie heeft verstrekkende gevolgen} voor medewerkers en is voor het management een belangrijk strategisch middel om de bedrijfsvoering te verbeteren. Er is weinig bekend over de vraag of de wijze van reorganiseren in tijden van economische crisis, meer of minder rekening houden met medewerkers, een effect heeft op de bedrijfsresultaten nadien. Meer inzicht op dit terrein is van belang voor zowel management als voor medewerkers en biedt sociale partners handvatten bij het vormgeven van het sociale karakter van een reorganisatie.

\section{Inleiding}

Reorganiseren wordt steeds gebruikelijker, en vindt niet alleen plaats om direct kosten te kunnen besparen. Er is veel bekend over de effecten van reorganiseren voor medewerkers (Aalbers \& Dolfsma, 2014), maar weinig over het effect op het bedrijfsresultaat nadien. Moeten bedrijven zich de stress en onzekerheid bij medewerkers aantrekken als voornaamste leidmotief en daarom op sociale wijze reorganiseren? De centrale vraag die we stellen in dit artikel is daarom: Hoe sociaal zou een bedrijf moeten reorganiseren om het bedrijfsresultaat kort na de reorganisatie te verbeteren? De keerzijde van deze vraag is: waarom kunnen de effecten van reorganisaties zo sterk van elkaar verschillen?
Tot in de jaren ' 80 reorganiseerden bedrijven om economische neergang om te zetten naar groei, en pas wanneer er geen andere, minder ingrijpende mogelijkheid meer was (Datta et al., 2010). Inmiddels is reorganiseren een veel gebruikte strategie geworden die regelmatig ingezet wordt en niet slechts wanneer er geen andere keus meer is (Datta \& Guthrie, 2010). Ook voor de huidige recessie reorganiseerden bedrijven regelmatig (Guthrie \& Datta, 2008).

Reorganisaties zijn er op gericht om de samenstelling en inzet van medewerkers van een bedrijf in overeenstemming te brengen met de (gewijzigde) strategische doelen van een bedrijf. Een onderdeel hiervan kan een afslankoperatie zijn, die vooral tot doel kan hebben het aantal medewerkers te reduceren (Gulati \& Puranam, 2009).

Reorganisaties zijn ingrijpend. Er is veel onderzoek gedaan met name naar de gevolgen van een reorganisatie voor de individuele medewerker. Daaruit is bekend dat reorganiseren door middel van personeelsafvloeiing medewerkers die vertrekken, maar ook zij die blijven, veel onzekerheid en stress bezorgen (Datta et al., 2010). Een reorganisatie waarbij meer rekening wordt gehouden met de gevolgen voor vertrekkend en blijvend personeel, een reorganisatie die socialer is, zou dan een beter resultaat kunnen hebben dan een reorganisatie die slechts gericht is op snelle kostenreductie en sanering. Hoewel het doel van reorganiseren vaak is om de productiviteit en concurrentiepositie van een bedrijf te verbeteren, wijst het beschikbare onderzoek uit dat het effect op het bedrijfsresultaat na afronding van de reorganisatie vaak onduidelijk is (Baily et al., 1996; Chadwick et al., 2004). Onderzoek, bijvoorbeeld dat van Love en Nohria (2005), neemt onvoldoende in overweging dat het verschil maakt hóe gereorganiseerd wordt, en niet alleen dát er gereorganiseerd wordt. Deze studie is daarom als exploratief te beschouwen. Met name de validiteit van de gebruikte indicatoren voor de mate waarin een reorganisatie als sociaal te bestempelen is, zou nader bepaald moeten worden. Wij vinden dat sociaal reorganiseren het bedrijfsresultaat negatief noch positief beïnvloedt, en dat 
het vooral goed is om de tijd te nemen voor een reorganisatie en er niet te laat aan te beginnen.

Dit artikel heeft een klassieke opbouw. Allereerst bespreken we de relevantie theorie, in paragraaf 2, dan zetten we uiteen welke data we gebruiken en hoe we die analyseren (paragraaf 3 ). In paragraaf 4 presenteren en interpreteren we de resultaten, waarna paragraaf 5 concludeert.

\section{Hoe sociaal moet een bedrijf reorganiseren?}

Het management van een bedrijf dat reorganiseert is zich veelal bewust van de onrust die een reorganisatie veroorzaakt. Die onrust kan er toe leiden dat juist medewerkers die het management graag wil behouden als eerste vertrekken (Shah, 2000; Sahdev, 2004). Bekend is ook dat verkeerd of onvolledig uitgevoerde reorganisaties ertoe kunnen leiden dat de doelstellingen niet gehaald worden, en een volgende reorganisatie zich als gevolg hiervan al snel aandient (Gilson et al., 2004). Vertrekkende, maar ook zittende medewerkers, verliezen hun motivatie, zetten zich minder in voor het gemeenschappelijke doel en zijn meer gericht op het behoud van de eigen positie (Mishra et al., 2009). Verkeerd uitgevoerde reorganisaties kunnen er ook toe leiden dat medewerkers ten onrechte ontslagen worden zodat ze nadien, als externen, tegen hogere kosten voor de organisatie, weer aangesteld worden omdat anders de bedrijfsvoering hapert (Guthrie \& Datta, 2008).

Waarom kunnen de effecten van reorganisaties zo sterk van elkaar verschillen, en waarom zijn medewerkers in sommige gevallen minder ontdaan dan in andere gevallen? Het beeld van een arbeidscontract als een incompleet contract waarbij tussen werkgever en werknemer wederzijds diensten worden geleverd (Akerlof, 1982) biedt aanknopingspunten. ${ }^{1}$ In een arbeidsovereenkomst kan uiteraard niet alle inzet die werkgevers van hun medewerkers verwachten, in alle mogelijke omstandigheden, en ver in de toekomst, op het moment van het aangaan van de overeenkomst worden bepaald. Omgekeerd kunnen ook niet alle verwachtingen van medewerkers ten aanzien van hun werkgever worden vastgelegd. Het gevolg is dat een arbeidsovereenkomst tot stand komt tegen het licht van de geldende wetten, en ook binnen de als billijk ervaren sociale normen. Naast een juridische overeenkomst is er sprake van een sociaal contract tussen werkgever en medewerker (Dolfsma, 1998). Ook als zich een situatie voordoet waarin één van de partijen extra inzet toont die niet geëist kan worden, zal een partij dat doen, in de verwachting dat de andere partij op enig moment in de nabije toekomst tot een wederdienst bereid is (Akerlof, 1982). De ene partij geeft, maar in de verwachting dat de andere partij zal reciproceren, ook al ligt er geen juridisch houdbaar contract - een kern van de sociale ruiltheorie waaruit ook de economische wetenschappen zijn ontsproten (Ekeh, 1974). Bij een reorganisatie kunnen medewerkers de extra inzet die niet in het arbeidscontract staat maar die wel in het sociale contract staat stopzetten. De wijze waarop en de mate waarin aan vooraf geldende sociale normen wordt voldaan bepaalt het sociale karakter van een sociaal plan. Hoe socialer een plan, hoe meer medewerkers geneigd zullen zijn toch de extra inzet te laten zien die uitgaat boven dat wat in het contract bepaald wordt.

De extra diensten die partijen van elkaar verwachten staan over het algemeen in verhouding tot waartoe zij in staat zijn (Mauss, 1954; Dolfsma, 1999). Contracten, juridisch of sociaal, kunnen met wederzijds goedvinden worden ontbonden, bijvoorbeeld als een bedrijf er slecht voorstaat en reorganisatie noodzakelijk is om te kunnen overleven. De situatie van een bedrijf op het moment dat gereorganiseerd wordt kan daarmee van belang zijn - van een bedrijf dat het ècht moeilijk heeft zal een minder sociaal plan om te reorganiseren eerder geaccepteerd worden dan van een bedrijf dat er nog redelijk goed voorstaat. In het laatste geval zullen medewerkers tot de conclusie komen dat het contract opgezegd is, waarna zij ook hun deel opzeggen. De inhoud van een sociaal of psychologisch contract tussen management en medewerkers kan uiteraard van bedrijf tot bedrijf verschillen.

Over het effect van de duur van een reorganisatie op het bedrijfsresultaat bestaan verschillende gedachten (Lamont et al., 1994; Swaen et al. 2004). Een snelle reorganisatie kan snel duidelijkheid geven en de stress als gevolg van onzekerheid over de toekomst bij medewerkers wegnemen. Medewerkers kunnen dat waarderen, ook als zij gedwongen worden te vertrekken. Een snelle reorganisatie kan ook een onzorgvuldig uitgedachte en uitgevoerde reorganisatie zijn (Cameron 1994; McClune et al., 1998). Hoe de duur van een reorganisatie het bedrijfsresultaat beïnvloedt is dus onduidelijk, terwijl de literatuur voor andere indicatoren voor de mate waarin een reorganisatie als sociaal te bestempelen duidelijker uitspraken doet.

\section{Onderzoeksopzet}

Er is sprake van een reorganisatie wanneer 20 of meer medewerkers hun baan verliezen. Bedrijven met minder dan 50 medewerkers kunnen ook een sociaal plan opstellen. Bedrijven die meer dan 50 medewerkers in dienst hebben zijn verplicht om een sociaal plan opstellen als zij reorganiseren. Dit bepaalt de Wet Melding Collectief Ontslag (WMCO). Een sociaal plan is als een contract tussen het management van een bedrijf en de medewerkers vertegenwoordigd door de vakbonden. Wanneer een van de partijen zich niet aan het contract houdt kan de ander deze partij voor het ge- 
recht dagen. Deze sociale plannen worden na goedkeuring regulier geregistreerd bij het Ministerie van Sociale Zaken en Werkgelegenheid - per jaar zijn dat er gemiddeld een honderdtal.

Van de bijna 300 bedrijven die in de periode 2004-2006 in Nederland reorganiseerden middels een sociaal plan, wisten we voor 71 bedrijven data over de aard van de reorganisatie uit de betreffende plannen af te leiden en te koppelen aan data (uit ORBIS) over bedrijfsresultaten. Beperkte beschikbaarheid van de bedrijfsresultaat-indicator voor zowel voor als na de reorganisatie zorgde voor een steekproef in plaats van een analyse van de gehele groep reorganisaties in de desbetreffende periode. Willekeurige spreiding van de steekproef over sectoren heen in combinatie met een verscheidenheid aan bedrijfsgroottes sluit sample bias uit. Het bedrijfsresultaat, de te verklaren variabele in dit onderzoek, is het rendement op activa (RoA), 1 jaar ná de reorganisatie. De mate waarin sprake was van nood bij start van de reorganisatie bepalen we door het RoA 1 jaar voordien te nemen. We nemen het natuurlijk logaritme. Door de RoA[-1] te nemen als controlevariabele is de kans kleiner dat gebeurtenissen die plaatsvonden vóór de reorganisatie het resultaat nadien bepalen (Espahbodi et al. 2000; Love \& Nohria, 2005). De mate waarin de reorganisatie als sociaal te bestempelen is, en volgens een heersend sociaal contract uitgevoerd wordt, bepalen we door een aantal variabelen op te nemen in de analyse. Deze variabelen stemmen overeen met wat de literatuur voorstelt (zie hierboven), en werden bevestigd in een aantal gevalstudies die we uitvoerden (onder meer Aalbers \& Dolfsma, 2013). Ten eerste de hoogte van de ontslagpremie voor vertrekkers, maar ook de scholing die hen in het vooruitzicht wordt gesteld om op ander werk buiten de organisatie voorbereid te worden. Ook kijken we in dit kader naar de hulp bij het zoeken naar ander werk (outplacement). Scholing van medewerkers die in de toekomst binnen de organisatie werkzaam blijven kan er voor zorgen dat zij zich beter in staat weten in de toekomst een nuttige bijdrage aan het bedrijfsresultaat te leveren. Voor deze variabelen wordt de hoogte van de bedragen die genoemd staan in het sociaal contract gebruikt. De duur van een reorganisatie kan verschillend worden uitgelegd. Een korte duur kan gunstig zijn omdat zo de pijn snel over is en er duidelijkheid komt ook als die ongunstig is. Anderzijds kan een langer durend plan op flexibiliteit van het management en oog voor detail wijzen. Baily et al. (1996) geeft aan dat reorganisaties per sector sterk kunnen verschillen, bijvoorbeeld omdat de ene sector een andere kostenstructuur of kapitaalintensiteit heeft dan de anderen. Om die reden nemen we sectordummies als controlevariabele mee. Sectorspecifieke ontwikkelingen kunnen zo (deels) worden uitgefilterd. De variabele sector is gecodeerd en geaggregeerd op basis van de SIC codering tot 5 sectorgroepen: productie, groothandel, ge- zondheidszorg, professionele- wetenschappelijke- en technische diensten, en overige sectoren. Dit niveau van aggregatie resulteert in een diversiteit aan bedrijfsgroottes en een variërende kapitaal- en kennisintensiteit binnen de sectorgroepen.

Tabel 1 presenteert de resultaten. We nemen eerst een model op met alleen de controlevariabelen. Model 2 neemt variabelen op die indiceren hoe sociaal het reorganiserende bedrijf is richting medewerkers die blijven. Scholing van personeel dat blijft en een langere reorganisatie wijzen op een grotere zorg in hun richting. Model 3 introduceert alleen de variabelen die duiden op de mate waarin reorganiserende bedrijven sociaal zijn richting vertrekkende medewerkers. Model 4 omvat alle relevante variabelen. Onze regressieresultaten (tabel 1) zijn robuust en stabiel: beta's en significantie indicaties wijzigen niet tussen modellen. Ook de correlatietabel (appendix) en controles voor mogelijke multicollinariteit (VIF scores < 1.13) en autocorrelatie middels een Durbin-Watson test voor de verschillende modellen geven geen reden tot afwijkende interpretatie van de resultaten. Toch zullen we voorzichtig moeten zijn met het trekken van conclusies, omdat de periode waarvoor we data beschikbaar hebben.

\section{Tabel 1 Bedrijfsresultaat ná reorganisatie (RoA [+1]): Helpt een Sociaal Plan?}

\begin{tabular}{|l|c|c|c|c|}
\hline Bedrijfsresultaat & $.440^{\star * *}$ & $.413^{\star * *}$ & $.429^{\star * \star}$ & $0.409^{* * \star}$ \\
(RoA [-1]) & $(4.269)$ & $(3.934)$ & $(4.039)$ & $(3.795)$ \\
\hline Sector & -.098 & -.186 & -.078 & -0.064 \\
& $(-.950)$ & $(-1.747)$ & $(-.732)$ & $(-0.601)$ \\
\hline Ontslagpremie & & & .032 & 0.056 \\
(vertrekkers) & & & $(.299)$ & $(.520)$ \\
\hline Scholing & & & -.008 & 0.092 \\
(vertrekkers) & & & $(-.073)$ & $(.836)$ \\
\hline Outplacement & & & .113 & -0.064 \\
(vertrekkers) & & & $(1.036)$ & $(-0.601)$ \\
\hline Scholing (blijvers) & & .167 & & 0.155 \\
& & $(1.566)$ & & $(1.413)$ \\
\hline Duur sociaal plan & & $.225^{\star *}$ & & $0.244^{\star *}$ \\
\hline N & & $(2.070)$ & & $(2.170)$ \\
\hline Adj. R & 71 & 71 & 71 & 71 \\
F-waarde & .176 & .274 & .158 & 0.257 \\
\hline
\end{tabular}

Reorganisatie op $\mathrm{t}=0$; gestandaardiseerde coëfficiënten; 2-tailed; t-waarden tussen haakjes; VIF waarden alle $<1.13 ;{ }^{*} /{ }^{* *} /{ }^{* *}$ significant op $10,5,1 \%$.

\section{Resultaten}

Opvallend genoeg leidt geen van onze variabelen die op sterke sociale elementen wijzen tot betere bedrijfs- 
resultaten in de periode direct na de reorganisatie. De beta's voor de drie variabelen die wijzen op een sociale manier van reorganiseren in de richting van vertrekkende medewerkers zijn niet statistisch significant. Het aanbieden van scholing aan blijvende medewerkers heeft ook geen gunstig effect op het bedrijfsresultaat van het reorganiserend bedrijf nadien. Sociaal reorganiseren kan een gunstig effect hebben op de gevoelens onder medewerkers, maar heeft dat niet per se op het bedrijfsresultaat. Anderzijds moet geobserveerd worden dat sociaal reorganiseren in ieder geval de bedrijfsresultaten niet negatief beïnvloedt: de beta's zijn positief, zij het niet significant. Wellicht vlakken positieve effecten en kosten elkaar uit. ${ }^{2}$

Het enige dat er op wijst dat het management er goed aan doet de overwegingen die spelen bij medewerkers in acht te nemen is het significante resultaat voor de duur van een reorganisatie: hoe langer een reorganisatie duurt, hoe beter het resultaat nadien wordt $(\beta=$ $0.244, \mathrm{p}<0,05)$. Dit is een opvallend resultaat omdat de duur van reorganiseren niet samenhangt met de financiële situatie voor de reorganisatie (RoA[-1]). Bedrijven die meer tijd nemen voor een reorganisatie zijn niet meer of minder in financiële problemen op het moment dat ze reorganiseren. Er kan beter ingespeeld worden op onvoorziene gebeurtenissen en gevolgen van de reorganisatie. Ook hebben medewerkers zo wellicht het gevoel dat zij het proces beter kunnen bijsturen, waardoor het gevoel van procedurele rechtvaardigheid minder geschonden wordt. Wellicht gaat het er wat betreft de duur van een reorganisatie vooral om dat medewerkers de tijd krijgen aan het idee van een reorganisatie te wennen. Ook spelen verschillen tussen sectoren hier mogelijk een rol. Een lange duur geeft wellicht betere mogelijkheden voor het betrekken van medewerkers en communiceren van de doelstellingen van de reorganisatie, en is mogelijk minder verstorend voor de dagelijkse organisatieprocessen. Nader onderzoek zou moeten bepalen hoe dit resultaat te verklaren is, en op welk moment dit effect afneemt en ombuigt: een zeer langdurige reorganisatie zal vermoedelijk geen gunstig effect op het bedrijfsresultaat meer hebben. Tegenvallende resultaten van reorganisaties, gerapporteerd in eerder onderzoek, worden zo wel verklaard: bedrijven hanteren graag een snelle, "quick-fix"-aanpak waardoor ze reorganisaties gebrekkig plannen (Cameron, 1994; McClune et al., 1998). Medewerkers kunnen aangeven dat zij lijden onder reorganisaties (vgl. Gandolfi, 2008; Parker \& McKinley, 2008), maar zullen, opvallend genoeg, hun bijdrage aan het behalen van resultaten van hun bedrijf niet terugschroeven wanneer een reorganisatie minder sociaal uitgevoerd wordt.

De positieve beta voor het bedrijfsresultaat 1 jaar voorafgaand aan de reorganisatie op het resultaat 1 jaar nadien duidt er wellicht op dat een bedrijf vooral moet reorganiseren op een moment dat het water nog niet tot aan de lippen staat. Nader onderzoek is echter noodzakelijk om naast deze kortetermijnimplicaties, ook de langetermijneffecten van een sociale reorganisatie uit te lichten.

\section{Conclusie}

Bedrijven reorganiseren met regelmaat - soms lijkt het wel alsof een bedrijf dat níet reorganiseert iets uit te leggen heeft (Gandolfi, 2009). Hoewel er veel bekend is over de vraag hoe medewerkers zich voelen tijdens een reorganisatie, is nauwelijks iets bekend over de vraag wat het gevolg van een reorganisatie is voor het bedrijfsresultaat. Verwacht mag worden dat een slechte sfeer bij medewerkers tijdens een reorganisatie ook zichtbaar wordt in achterblijvende bedrijfsresultaten (Shah, 2002). In tegenstelling tot onze initiële verwachting, vinden wij dat de mate waarin een reorganisatie een sociaal karakter heeft, het bedrijfsresultaat nadien niet op de korte termijn verbetert. Alleen een lange duur van een reorganisatie is goed voor het bedrijfsresultaat nadien, zij het wederom op de korte termijn, in de directe afloop van de reorganisatie. Een fase die als bijzonder kritisch voor het doorstarten van een organisatie wordt beschouwd. Hoewel nader onderzoek uiteraard vereist is, gegeven de beperkingen in de data die we kennen ${ }^{3}$ en de mogelijkheid dat de gevonden resultaten samenhangen met de conjunctuur van het moment, lijkt het er op dat een bedrijf niet pas moet reorganiseren als het water aan de lippen staat.

Dr. drs. H.L. Aalbers is assistant professor Strategy \& Innovation bij het Institute for Management Research aan de Radboud Universiteit Nijmegen en tevens verbonden aan het Centre for Organization Restructuring.

Prof. dr. W.A. Dolfsma is hoogleraar Strategy \& Innovation aan de Faculteit Economie en Bedrijfskunde van de Rijksuniversiteit Groningen; director SOM research programma Innovation \& Organization en tevens verbonden aan het Centre for Organization Restructuring. Onze dank gaat uit naar Niels van Boekel voor zijn assistentie bij de datapreparatie en naar Olivier Stam voor de bijdrage van zijn gevalstudie. 


\section{Appendix: Beschrijvende statistieken}

\section{Tabel 2 Beschrijvende statistieken en correlatie matrix}

\begin{tabular}{|c|c|c|c|c|c|c|c|c|c|c|}
\hline & Variabelen & Gemiddelde & Std. Dev. & 1 & 2 & 3 & 4 & 5 & 6 & 7 \\
\hline 1 & Bedrijfsresultaat (RoA [1]) & 1,26 & ,25260 & & & & & & & \\
\hline 2 & Bedrijfsresultaat (RoA [-1]) & 1,34 & ,31752 &, $468^{\star \star \star}$ & & & & & & \\
\hline 3 & Sector & 3,69 & 1,460 &,- 062 & ,092 & & & & & \\
\hline 4 & Scholing (blijvers) & ,38 & ,489 &, $277^{\star \star}$ & ,205* & 147 & & & & \\
\hline 5 & Duur sociaal plan & 1,76 & ,21560 & ,283** & 168 & $271^{\star \star}$ & $234^{\star \star}$ & & & \\
\hline 6 & Ontslagpremie (vertrekkers) & 1,521 & ,79028 & ,018 &,- 103 &,- 031 &,- 040 &,- 058 & & \\
\hline 7 & Outplacement (vertrekkers) & 65 & ,481 & $197^{*}$ & 130 &,- 158 & 152 &,- 027 & ,227* & \\
\hline 8 & Scholing (vertrekkers) & ,69 & ,466 & ,032 & ,070 & ,046 & ,086 &, $216^{\star \star}$ & ,018 & ,080 \\
\hline
\end{tabular}

\section{Noten}

Hier wordt vanuit de psychologie ook wel gesproken van een psychologisch contract (Bal et al. 2010).

2. De positieve effecten van op een sociale wijze reorganiseren zouden ook op iets langere termijn pas kunnen blijken, maar dan wellicht statistisch niet meer te traceren zijn.

3 Wanneer meer observaties beschikbaar zouden zijn kan ook gecontroleerd worden voor bijvoorbeeld een mogelijk verschil tussen beurs- genoteerde en niet-beursgenoteerde bedrijven, of bijvoorbeeld familiebedrijven versus non-familiebedrijven. De aankondiging van een reorganisatie kan sterk verschillen tussen deze typen bedrijven.

\section{Literatuur}

- Aalbers, R., \& Dolfsma, W. (2013). Innovation resilience despite downsizing: Benefits from positioning in the formal and informal network. Paper presented at the 20th International Product Development Management Conference 2013, June, Dauphine University, Paris, France

- Aalbers, R., \& Dolfsma, W. (2014). Innovation despite reorganization. Journal of Business Strategy, 35(2), forthcoming.

- Akerlof, G.A. (1982). Labor contracts as partial gift exchange. Quarterly Journal of Economics, 97(4), 543-569.

- Baily, M.N., Bartelsman, E.J., \& Haltiwanger, J. (1996). Downsizing and productivity growth: Myth or reality? Small Business Economics, 8, 259-278

- Bal, P.M., Jansen, P., Velde, M. van der, Lange, A. de, \& Rousseau, D. (2010). De rol van toekomstperspectief in het psychologisch contract van oudere werknemers. Maandblad voor Accountancy en Bedriffseconomie, 84(7/8), 381-394.

- Cameron, K.S. (1994). Strategies for successful organizational downsizing. Human Resource Man-agement, 33(2), 189-211.
- Chadwick, C., Hunter, L.W., \& Walston, S.L. (2004). Effects of downsizing practices on the performance of hospitals. Strategic Management Journal, 25, 405-427.

- Datta, D. K., Guthrie, J. P., Basuil, D., Pandey, A. (2010). Causes and effects of employee downsizing. Journal of Management, 36(1):281-348.

- Dolfsma, W. (1998). Labor relations in changing capitalist economies. Journal of Economic Issues, 32(2), 631-638.

- Dolfsma, W. (1999). Wie zoet is krijgt lekkers. Economisch Statistische Berichten, 84(4232), December 3, 897-898.

- Ekeh, P.P. (1974). Social exchange theory: the two traditions. London: Heinemann.

- Espahbodi, R., John, T.A., \& Vasudevan, G. (2000). The effects of downsizing on operating performance. Review of Quantitative Finance and Accounting, 15(2), 107-126.

- Gandolfi, F. (2008). Learning from the past: Downsizing lessons for managers. Journal of Management Research, 8(1), 3-17.

- Gandolfi, F. (2009). Unravelling downsizing What do we know about the phenomenon? Review of International Comparative Manage- ment, 10(3), 414-423.

- Gilson C., Hurd, F., \& Wagar, T. (2004). Creating a concession climate: the case of the serial downsizers. International Journal of Human Resource Management, 15 (6), 1056 1068

- Gulati, R., \& Puranam, P. (2009). Renewal through reorganization: The value of inconsistencies between formal and informal organization. Organization Science, 20(2), 422-440.

- Guthrie, J.P., \& Datta, D.K. (2008). Dumb and dumber: The impact of downsizing on firm performance as moderated by industry conditions. Organization Science, 19(1), 108-123.

- Lamont, B.T., Williams, R.J., \& Hoffman, J.J. (1994). Perfomance during 'M-form' reorganization and recovery time: The effects of prior strategy and implementation speed. Academy of Management Journal, 37(1), 153-166.

- Love G.E., \& Nohria, N. (2005). Reducing slack: the performance consequences of downsizing by large industrial firms. Strategic Management Journal, 26, 1087-1108.

- Mauss, M. (1954) [2000], The gift. New York: Norton.

- McClune, J.T., Beatty, R.W., \& Montagno, R.V. 
(1998). Downsizing: Practices in manufacturing firms. Human Resource Management Journal, 27, 145-161.

- Mishra, A.K., Mishra, K.E., \& Spreitzer, G.M. (2009). Downsizing the company without downsizing morale. MIT Sloan Management Review, 50(3), 39-44.

- Parker, T., \& McKinley, W. (2008). Layoff agen- cy: A theoretical framework. Journal of Leadership \& Organizational Studies 15(1),46-58.

- Sahdev, K. (2004). Revisiting the survivor syndrome: The role of leadership in implementing downsizing. European Journal of Work and Organizational Psychology, 13(2), 165-196.

- Shah, P. (2000). Network destruction: The structural implications of downsizing. Acade- my of Management Journal, 43, 101-112.

- Swaen, G.M.H., Bultmann, U., Kant, IJ., \& Amelsvoort, L. van (2004). Effects of job insecurity from a workplace closure threat on fatigue and psychological distress. Journal of Occupational and Environmental Medicine, 46(5), 443-449. 